\title{
Penerapan Tema Arsitektur Neo Vernakular pada Fasilitas Seni Teater Boneka di Kota Surabaya
}

\author{
Dewi Syahputri Rahayu ${ }^{1}$, Broto W. Sulistyo ${ }^{2}$, Dian P. E. Laksmiyanti ${ }^{3}$ \\ 1,2,3Jurusan Arsitektur, Fakultas Teknik Sipil dan Perencanaan, Institut Teknologi Adhi Tama Surabaya, \\ Surabaya, Indonesia \\ Email: 1 dewisyhptr28@gmail.com, 2 brotows@gmail.com
}

\begin{abstract}
Some communities, performances, workshops of Artists or Art Community Puppet Theatre located in the City of Surabaya.. In addition to the known by many community and art activities, Surabaya is also known as the City Education Center in East Java. As is the case with functions rather than the Art of Puppet Theater that can play a role in education because it is the medium of communication is the most good for all ages. However, these activities are less exposed so that less interest from the public. The design of the Art Facilities Puppet Theatre in the City of Surabaya, the Theme of the architecture of the Neo Vernacular expected to be the container for the artists or the community and the community to collaborate and develop as well as being a container or media new educational for the people of the City of Surabaya, which is able to keep lifting the essence of the city coupled with the style of the present. The concept of the micro-fabric of the land "Focus on the performance area" with a circulation of linear which can drain the visitors from the starting point where the dish is the beginning of the Art of Puppet Theater to the end point which is the dish more current. Micro-form "Joglo Jawa Castle" obtained from the iconic Art of Puppet Theatre form of castle represented using custom of Joglo combined with local materials. Micro Space "Modern Natural" is used to reflect the nature and development of the Art of Puppet Theatre as well as implementation of Traditional Javanese Architecture.
\end{abstract}

Keywords: Puppet Theater Art, Facilities, Surabaya, Neo Vernacular

\begin{abstract}
Abstrak. Beberapa komunitas, pertunjukan, workshop dari Seniman atau Komunitas Seni Teater Boneka terdapat di Kota Surabaya.. Selain dikenal dengan banyak komunitas dan kegiatan seni, Surabaya juga dikenal sebagai Kota Pusat Pendidikan di Jawa Timur. Seperti halnya dengan fungsi dari Seni Teater Boneka yang dapat berperan dalam hal pendidikan karena merupakan media komunikasi paling baik untuk segala usia. Namun kegiatan tersebut kurang menunjukkan keberadaannya sehingga kurang mendapatkan minat dari masyarakat. Perancangan Fasilitas Seni Teater Boneka di Kota Surabaya dengan Tema arsitektur Neo Vernakular diharapkan dapat menjadi wadah untuk para seniman atau komunitas dan masyarakat untuk berkolaborasi dan mengembangkan serta menjadi wadah atau media edukasi baru untuk masyarakat Kota Surabaya, yang mampu tetap mengangkat esensi lokal yang bersanding dengan gaya kekinian. Konsep mikro tatanan lahan "Memusat pada area pertunjukan" dengan sirkulasi linear yang dapat mengalirkan pengunjung dari titik awal dimana merupakan sajian awal mula Seni Teater Boneka hingga titik akhir yang merupakan sajian lebih terkini. Mikro bentuk "Joglo Jawa Kastil" didapatkan dari ikon Seni Teater Boneka bentuk kastil yang direpresentasikan menggunakan gubahan dari Joglo yang dikombinasikan dengan material lokal. Mikro Ruang "Natural Modern" digunakan untuk dapat mencerminkan sifat serta perkembangan Seni Teater Boneka serta implementasi dari Arsitektur Tradisional Jawa.
\end{abstract}

Kata Kunci: Seni Teater Boneka, Fasilitas, Kota Surabaya, Neo Vernakular

\section{Pendahuluan}

Seni teater boneka merupakan salah satu budaya yang telah menjadi bagian dari kehidupan masyarakat Indonesia. Sejak dahulu, seni teater boneka di Indonesia lebih dikenal dengan sebutan wayang yang memiliki fungsi sebagai ritual serta penyebaran agama. Namun seiring dengan berkembangnya zaman seni teater boneka lebih dipergunakan sebagai alat komunikasi dalam perihal pendidikan serta hiburan. Menurut Nalan (2015) disebutkan bahwa setiap tanggal 21 Maret ditetapkan sebagai Hari Teater Boneka sedunia oleh Javad Zolfaghari yang membuat semakin maraknya para komunitas dan seniman teater boneka baru yang lahir dan terus mengembangkan dari berbagai segi 
seperti fungsi, bentuk, pesan, dan cara pembawaannya. Beberapa contoh teater boneka hasil transformasi yang ada di Indonesia diantaranya Si Unyil, Si Komo, Wayang Motekar dari Bandung, Wayang Tapiv dari Bandung, dan Papermoon Puppet Theatre.

Di Kota Surabaya, terdapat 2 jenis seni teater boneka yaitu Seni Teater Boneka Kontemporer dan Tradisional yang digagas oleh Dalang Cilik serta Komunitas Kampus. Hal ini menjadi bukti bahwa Kota Surabaya telah berulang kali dilaksanakan kegiatan pementasan secara lokal dan menjadi tujuan para komunitas atau seniman untuk berkunjung dalam hal melakukan sharing pementasan, mengadakan workshop dan pendidikan. Namun kegiatan tersebut kurang menunjukkan keberadaannya dan kurang diminati oleh masyarakat karena belum memiliki fasilitas khusus untuk mengangkat, memperkenalkan dan mengembangkan Seni Teater Boneka di Kota Surabaya. Padahal dari beberapa pertunjukan, pembelajaran serta riset oleh beberapa ahli diketahui bahwa Seni Teater Boneka terbukti sangat efisien dan efektif sebagai media komunikasi dalam pembelajaran baik dari skala anak-anak hingga dewasa, apalagi Kota Surabaya memiliki julukan sebagai pusat dari Kota Pendidikan.

Oleh karena itu, harapannya dengan menyediakan Kompleks Fasilitas Seni Teater Boneka di Kota Surabaya dapat menjadikan wadah untuk para seniman, komunitas atau bahkan masyarakat di Kota Surabaya untuk berkumpul, berkolaborasi dan mengembangkan serta menjadi sarana edukasi baru untuk masyarakat Kota Surabaya.

Pada rancangan kompleks bangunan ini tema yang digunakan adalah Arsitektur Neo Vernakular. Menurut (Jenck, 1991) dalam bukunya Language of Post-Modern Architecture bahwa Arsitektur Neo Vernakular merupakan gaya yang menghidupkan kembali suasana atau elemen tradisional dengan pengolahan bentuk secara lebih kekinian dengan ciri-ciri: (a) Pemakaian atap miring. (2) Batu Bata sebagai elemen lokal. (3) Susunan massa yang indah. Selain itu Erdiono (2011) juga menyebutkan bahwa Arsitektur Neo Vernakular merupakan sebuah upaya dalam akulturasi budaya dengan perubahan-perubahannya akibat adanya era yang lebih modern dengan tanpa meninggalkan jejak Arsitektur Lokalnya dengan cara memilah setiap nilai-nilai didalamnya. Pola perubahan yang terjadi mempunyai paradigma-paradigma seperti: a) Bentuk dan Maknanya Tetap; b) Bentuk Tetap dengan Makna Baru; c) Bentuk dan Maknanya Baru (Berubah); d) Bentuk Baru dengan Makna Tetap.

Arsitektur Vernakular Jawa memiliki ciri khas yaitu sistem pemasangan setiap sendi rangka pada bangunan Joglo tidak menggunakan pengait buatan melainkan menggunakan sistem "cathokan". Selain itu Arsitektur Vernakular Jawa juga memiliki berbagai macam ragam hias yang digunakan pada rumahnya, ragam hias tersebut meliputi flora, fauna dan alam.

Menurut Santosa (2008) dalam Buku Seni Teater Jilid 2 disebutkan bahwa Seni Teater Boneka adalah jenis cabang seni teater yang mengalami perkembangan akibat adanya perubahan mengikuti zamannya, keduanya di kenal dengan menggunakan boneka sebagai media pementasannya. Kemunculannya diawali dengan hadirnya wayang kulit sebagai salah satu bentuk seni dan diyakini berakar pada budaya kuno, yang berusia lebih dari 3000 tahun. Seiring berkembangnya zaman, seni teater boneka mengalami perkembangan yang dimaksud yaitu mampu bereksplorasi dari bentuk, cerita, memadukan antara beberapa bidang seni. Menurut Latshaw (2000), dalam bukunya "The Complete Book of Puppetry" disebutkan bahwa jenis-jenis dalam seni teater boneka serta cara memainkannya. Jenis dan Cara memainkannya seperti: (1) Jenis seni teater boneka (a) teater boneka tradisional (b) teater boneka kontemporer (2) Cara bermain seni teater boneka (a) boneka tongkat (b) boneka bayangan (c) boneka tangan (d) boneka tali (e) boneka badan.

Menurut data Bappeda Jawa Timur, Kota Surabaya telah berdiri sejak tahun 1293 yang terletak di daerah Pantai Utara, Provinsi Jawa Timur. Kota Surabaya, terkenal sebagai kota pelabuhan yang secara tidak langsung menjadikan sebagai kota Perdagangan dan Jasa. Saat ini, Kota Surabaya memiliki kesenian teater boneka yang memiliki fungsi sebagai sarana pendidikan dan kebudayaan namun keberadaanya kurang diminati dan dikenal oleh masyarakat serta bentuknya yang kurang berkembang. Jenis teater boneka tersebut yaitu wayang kulit dan seni teater boneka kontemporer yang digagasi oleh para komunitas-komunitas kampus dan seniman baru yang peduli akan perkembangan pendidikan dan kebahagiaan anak. Kota Surabaya memiliki julukan sebagai Kota Pendidikan, terbukti dengan adanya banyak fasilitas pendidikan serta penunjang. Berbagai upaya dilakukan untuk dapat terus mengembangkan media pembelajaran dalam pendidikan, salah satunya melalui media teater boneka. 
Menurut Malaka (2015) dalam artikel "Mendaulat Kota Surabaya sebagai Kota Pendidikan" menegaskan bahwa Sastrawan Afrizal Malna mengatakan ciri dari kota yang maju adalah mendapatkan perhatian penuh pemerintahnya terhadap perkembangan seni, budaya dan pendidikan. Salah satunya terhadap bidang Kesenian. Saat ini pementasan budaya di Kota Surabaya mendapatkan antusias oleh pengunjung tidak hanya dari lokal Kota Surabaya melainkan juga berasal dari luar Kota Surabaya.

\section{Metode Penelitian}

Metode perancangan merupakan sebuah proses yang digunkan dalam merancang, berupa kerangka berpikir dan hasil rancangan yang sesuai. Metode yang di gunakan yaitu metode deskriptif, studi kasus literatur dan studi kasus lapangan dengan metode rancangan tersebut diharapkan dapat menghasilkan sebuah rancangan yang maksimal dan mampu memenuhi kebutuhan fungsi, estetika, aspek arsitektural, aspek struktur dan aspek lainnya.

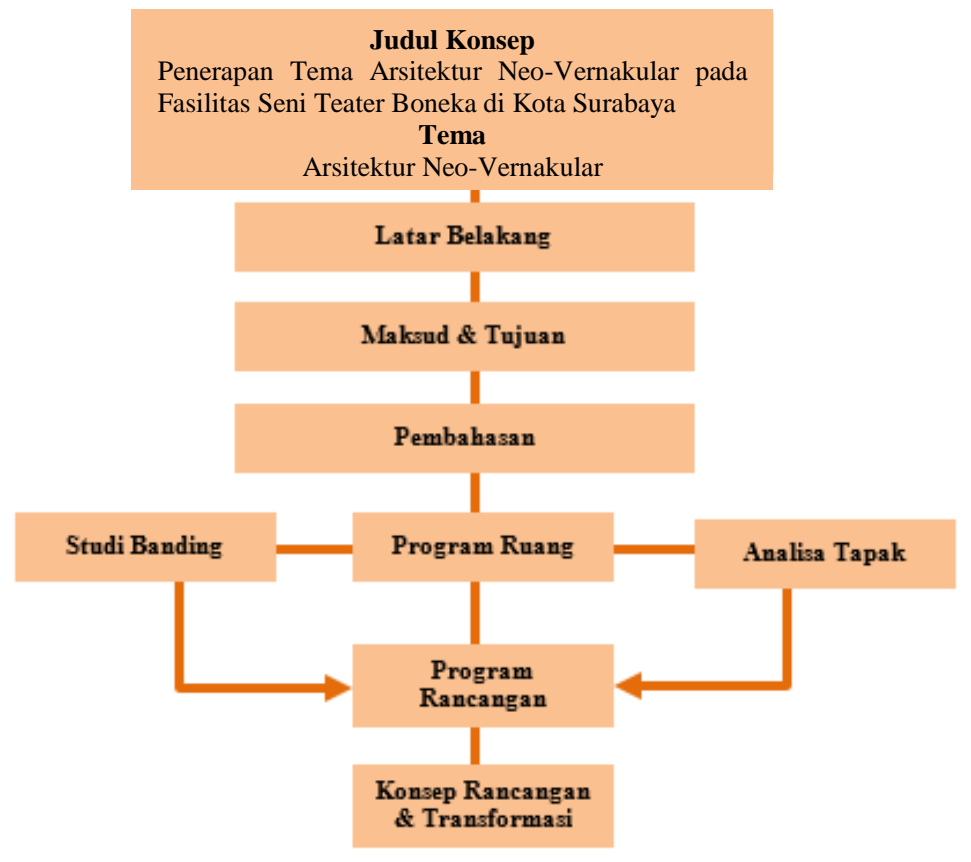

Gambar 1. Diagram Metode Penelitian

\section{Hasil dan Diskusi}

Lokasi lahan perancangan Fasilitas Seni Teater Boneka terletak di Jl. Arif Rahman Hakin, Kota Surabaya dengan luas lahan \pm 3 Ha serta kondisi tapak relatif datar. Setelah melakukan beberapa analisis terhadap lahan maka dapat dihasilkan kesimpulan bahwa lahan tersebut berpotensial untuk dibangunnya sebuah Fasilitas Seni Teater Boneka karena lahan tersebut berdampingan dengan gedung-gedung pendidikan yang sesuai dengan target utama dalam proyek ini.

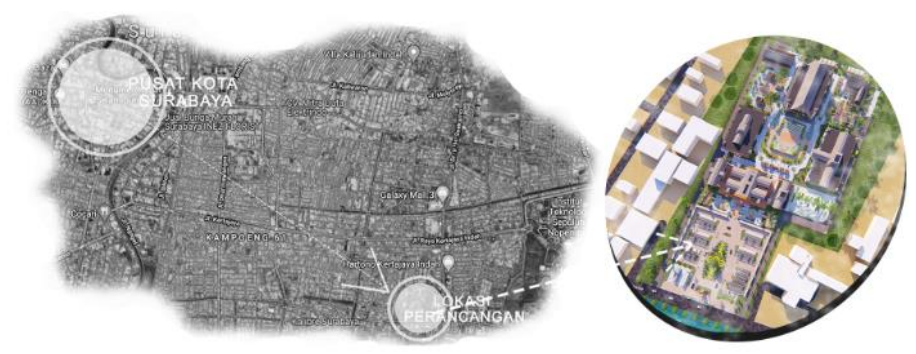

Gambar 2. Mapping Site Perancangan 
Sebelum terjadinya proses perancangan, peneliti juga melakukan observasi dengan melakukan pengamatan secara langsung maupun melalui website terhadap objek yang memiliki persamaan jenis bangunan maupun tema yang dijadikan acuan dalam perancangan. Objek observasi yang dipilih adalah sebagai berikut:

Taman Budaya Cak Durasim terletak di Jalan Genteng Kali No. 85, Surabaya dengan lahan 1,4 hektar yang dikelola oleh UPT Taman Budaya Jawa Timur. Pemilihan objek tersebut sebagai studi banding lapangan adalah Kompleks Taman Budaya Cak Durasim merupakan salah satu tempat pagelaran budaya terutama mengenai Seni Teater Boneka Tradisional Wayang Kulit.

Taman Budaya Wilwatikta yang teletak di Jl. Sumber Gedang, Pandaan dengan luas area 12,3 Hektar. Pemilihan objek studi kasus dapat mewakili tema serta objek perancangan yang dipilih. Memilih terapan konsep wisata serta memiliki view baik menghadap arah pegunungan penanggungan sehingga kompleks tersebut memiliki daya tarik tersendiri.
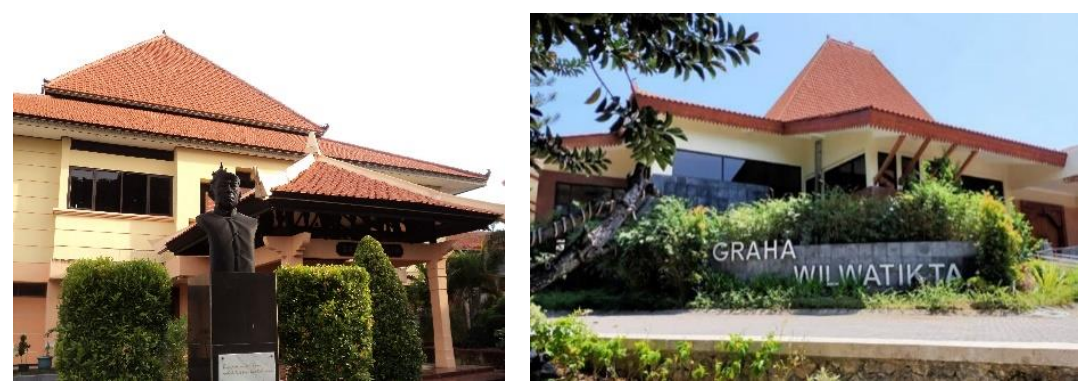

Gambar 3. Taman Budaya Cak Durasim (Kiri); Taman Budaya Wilwatikta (Kanan)

Studio Papermoon Puppet Theater merupakan studio milik komunitas Seni Teater Boneka Kontemporer yang berlokasi di Sembungan Bangunjiwo, Yogyakarta dengan luas area $500 \mathrm{~m}^{2} \& 250$ $\mathrm{m}^{2}$. Komunitas tersebut mampu menarik perhatian masyarakat Indonesia dengan segala program dan bentuk pertunjukannya. Biasanya sering mengadakan kegiatan workshop, Pertunjukan, Sharing dengan kuratornya setelah pementasan. Hal tersebut menjadi acuan peneliti dalam merancangan proyek Fasilitas Seni Teater Boneka untuk dapat menerapkan bagaimana cara mereka dapat menarik minat masyarakat.

National Bunraku Theater merupakan sebuah bangunan yang mempunyai fungsi kompleks dalam memperkenalkan Seni Teater Boneka yang merupakan salah satu ciri kebudayaannya. Objek tersebut terletak di Osaka Jepang dengan luas bangunan 3.924.874 $\mathrm{m}^{2}$. Memiliki fungsi ruang sebagai gedung pertunjukan, galeri, ruang workshop, cafetaria, dsb.

Djoglo \& Djati Bungalow merupakan kompleks area wisata kecil dengan fungsi sebagai café serta area penginapan yang terletak di Perumahan Araya Malang dengan luas area $13.302 \mathrm{~m}^{2}$. Objek ini dipilih karena terkait dengan tema rancangan yang perwujudannya diaplikasikan pada bentuk serta ruang dari gubahan Arsitektur Tradisional Jawa yang dibuat secara kekinian.
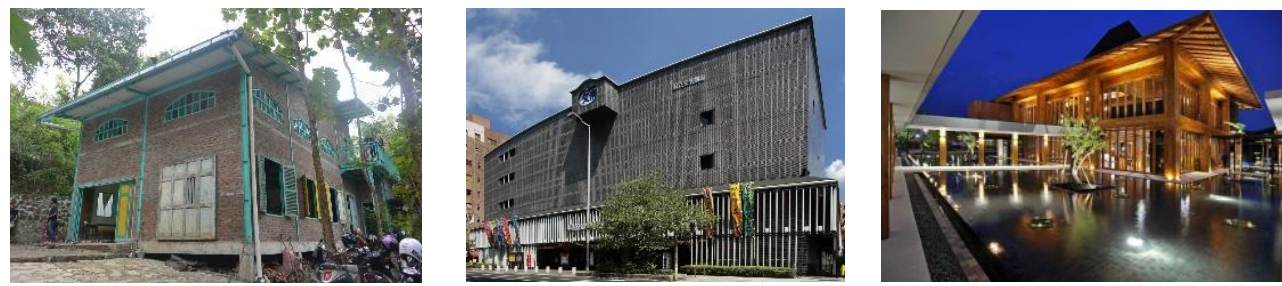

Gambar 4. Studio Papermoon Puppet Theater (Kiri); National Bunraku Theater (Tengah); Djoglo Djati Bungalow (Kanan)

Berdasarkan 5 (lima) studi banding yang telah diobservasi baik terkait objek maupun tema rancangan. Maka dapat disimpulkan seperti yang ada pada Tabel 1, bahwa: 
Tabel 1. Hasil Observasi Studi Kasus

\begin{tabular}{cl}
\hline Kesimpulan Studi Banding \\
\hline 1. & Tatanan lahan dibuat memusat pada area pertunjukan sebagai representasi daripada pusat kegiatan hasil observasi komunitas \\
\hline 2. & $\begin{array}{l}\text { Suatu komplek bangunan yang lengkap : area pertunjukan, galeri, pengembangan, penginapan, dsb agar dapat mengikat } \\
\text { minat masyarakat }\end{array}$ \\
\hline 3. & Neo Vernakular yang memiliki bentuk dominan kubus / balok dengan warna cream, coklat dan representasi dari Joglo \\
\hline 4. & $\begin{array}{l}\text { Ruang dibuat terarah dan jelas akan fungsi didalamnya serta dibuat transparan dengan kaca hingga titik lantai agar memiliki } \\
\text { kesan interaksi dengan pengunjung. }\end{array}$ \\
\hline 5. & Menjadikan area public di depan untuk memikat minat masyarakat yang datang. \\
\hline
\end{tabular}

Tema Arsitektur Neo Vernakular dipilih untuk dijadikan sebagai acuan tema pada rancangan Fasilitas Seni Teater Boneka di Kota Surabaya dengan maksud dapat menjadi ikon budaya terbaru di Kota Surabaya dengan pengolahan dari Arsitektur Tradisional Jawa yang diwujudkan dengan melalui transformasi gubahan.

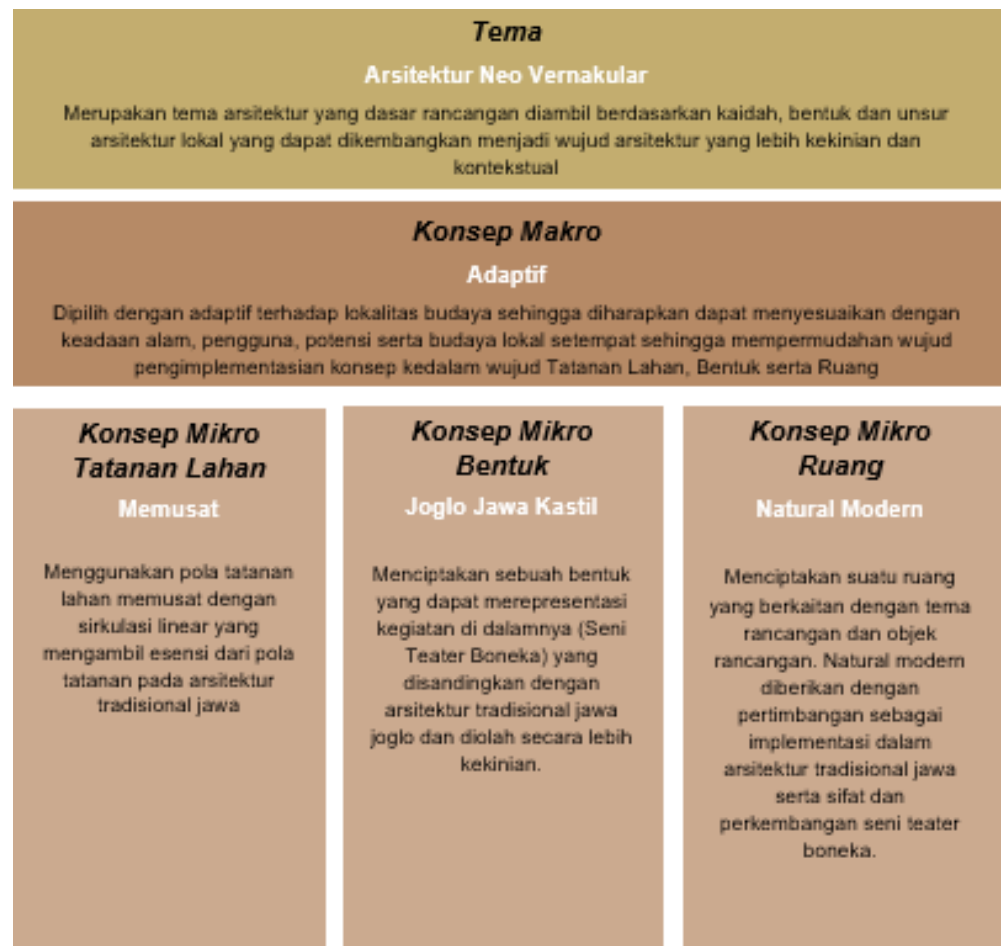

Gambar 5. Diagram Perumusan Konsep Rancangan

Pemilihan Konsep Makro “Adaptif” dengan maksud untuk menyelaraskan antara tema dengan objek rancangan. Selain itu juga dapat menyesuaikan dengan sifat daripada manusia secara umum yang menyukai hal-hal berbau kekinian, serta kurang minat dengan aroma budaya. Sehingga Makro "Adaptif" dirasa tepat untuk penerapan dalam 1 kompleks yang dirancang untuk dapat memuat perkembangan Seni Teater Boneka dengan pengolahan bentuk serta sirkulasi yang secara tidak langsung dapat mengantarkan dan memikat minat masyarakat setempat akan budaya yang telah ada sejak dahulu dan menjadi inovasi terbaru untuk media pendidikan dengan basis budaya.

Mikro Konsep "Memusat pada Gedung Pertunjukan" pada Tata Lahan merupakan salah satu upaya untuk tetap dapat menerapkan esensi dari pola tatanan pada rumah Tradisional Jawa sehingga dari pola tatanan tersebut menghasilkan sirkulasi yang linear, dimana sistem sirkulasi ini dapat mengalirkan pengunjung dari titik awal dimana merupakan sajian awal mula Seni Teater Boneka hingga titik akhir yang merupakan sajian lebih terkini. Gambar berikut ilustrasi tentang transformasi pola tatanan lahan Arsitektur Tradisional Jawa yang disajikan secara implementasi kedalam lahan perancangan. 

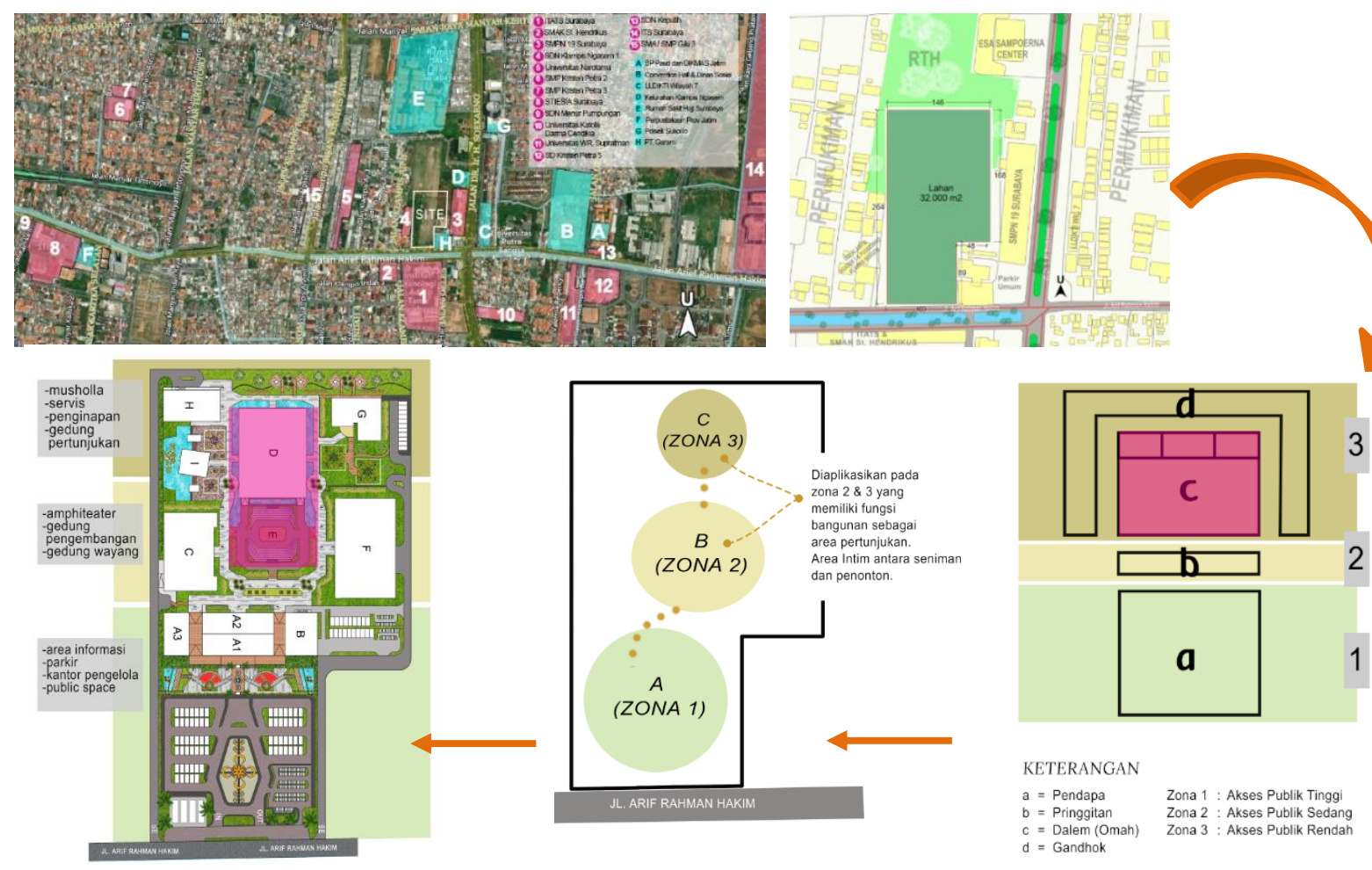

Gambar 6. Transformasi Tatanan Lahan

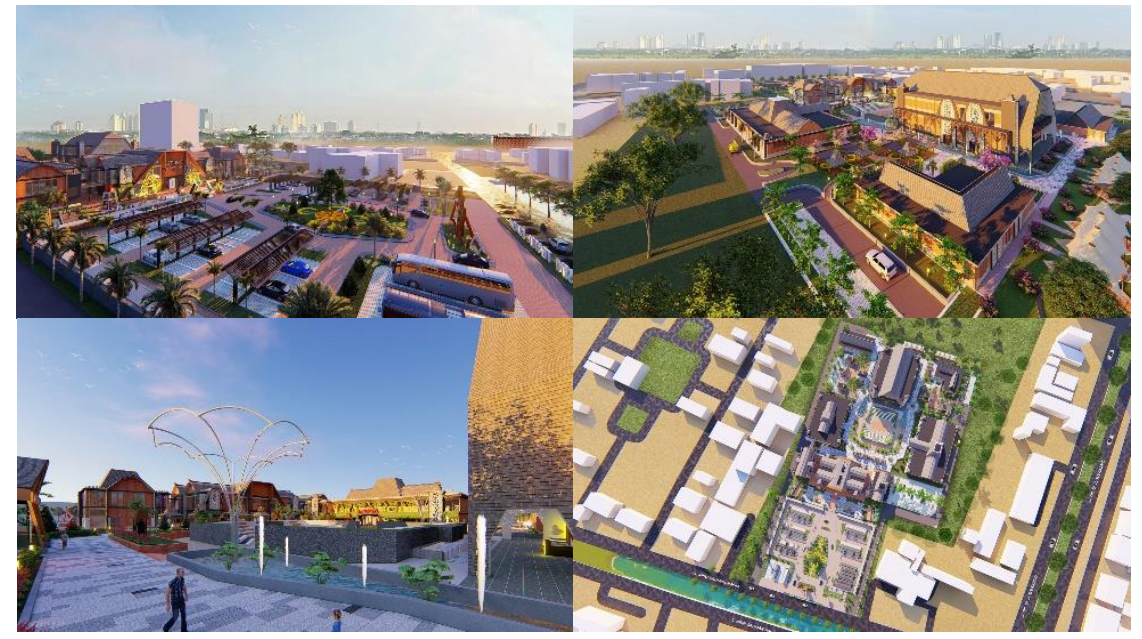

Gambar 7. Perspektif Tatanan Lahan

Mikro Konsep "Joglo Jawa Kastil” pada Tata Bentuk merupakan sebuah upaya merepresntasi Arsitektur Tradisional Jawa Joglo yang disandingkan dengan Ikon kastil dari Seni Teater Boneka. Upaya tersebut dilakukan dengan tahap gubahan baik dari material, dan bentuknya. Sehingga dapat dihasilkan sebuah visual bentuk yang tetap mengangkat lokalitas budaya, objek yang terkait. Diharapkan dikemudian hari dapat memikat masyarakat setempat untuk berkunjung. Gambar berikut menunjukkan transformasi Arsitektur Tradisional Jawa Joglo yang diaplikasikan pada bentuk rancangan. 


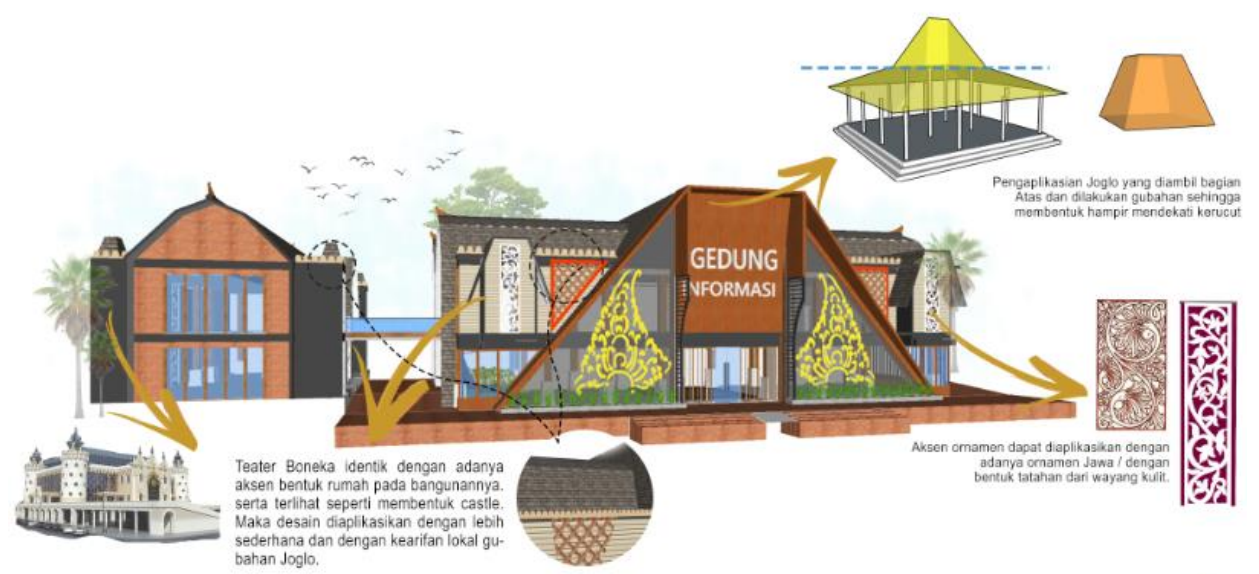

Gambar 8. Transformasi Bentuk Rancangan

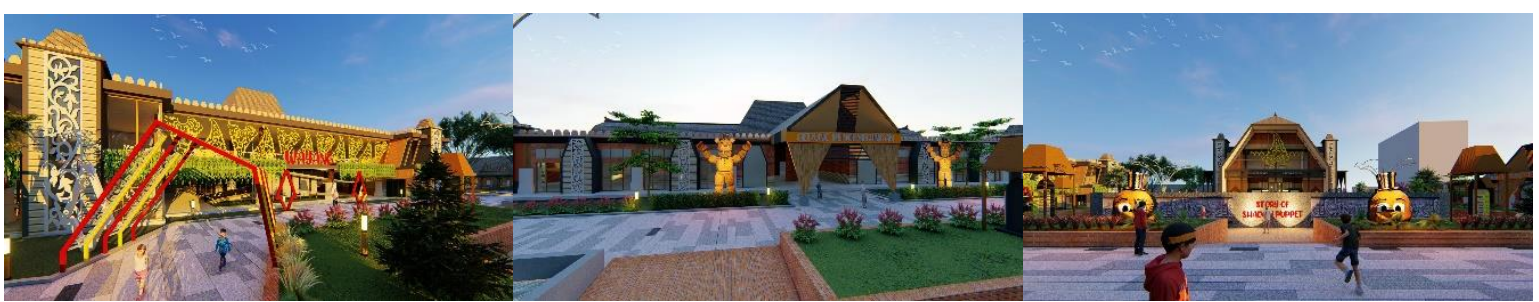

Gambar 9. Rancangan Bentuk

Mikro Konsep "Natural Modern” pada Ruang dengan maksud untuk dapat menciptakan sebuah ruang yang berkaitan dengan tema dan objek rancangan. Natural Modern dipilih dengan pertimbangan sebagai implementasi dalam Arsitektur Tradisional Jawa serta sifat dan perkembangan seni teater boneka. Penggunaan warna-warna netral yang disandingkan dengan warna kayu serta ornamen Jawa dan wayang mengikuti daripada fungsi ruang yang bersangkutan merupakan sebuah upaya untuk tetap menyeimbangkan antara ruang luar dengan ruang dalam pada bangunan. Gambar berikut menunjukkan transformasi penerapan warna pada Arsitektur Tradisional Jawa yang disandingkan dengan warna modern untuk disesuaikan dengan tema perancangan.
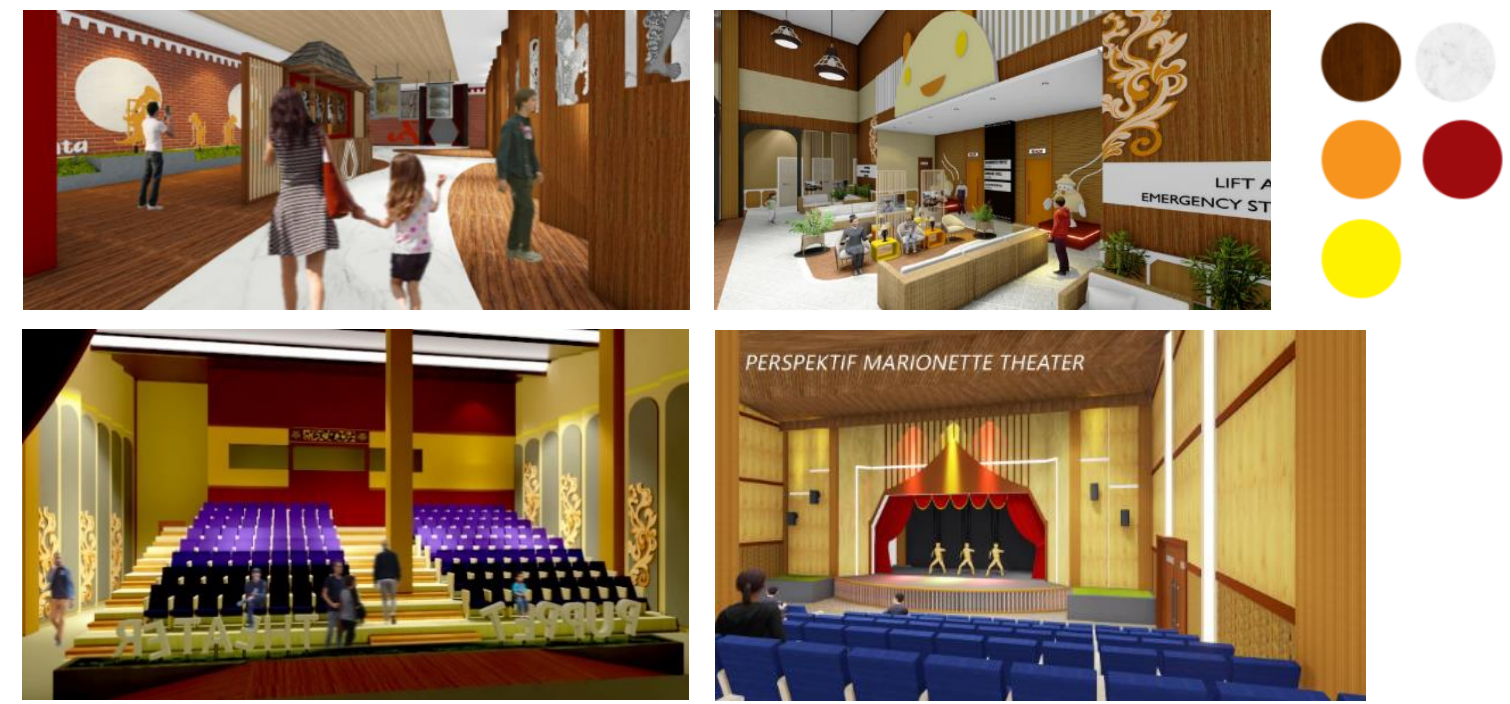

Gambar 10. Transformasi Ruang Rancangan

\section{Kesimpulan}

Kota Surabaya memiliki potensi yang tinggi dalam hal seni budaya dan pendidikan. Hal itu dibuktikan dengan seni dan pendidikan selalu berjalan beriringan. Seiring dengan perkembangannya, 
seniman di Kota Surabaya mengupayakan untuk terus dapat berkontribusi dalam bidang pendidikan dengan cara up to date menggunakan transformasi media boneka yang telah ada menjadi lebih kekinian tanpa menghilangkan asalnya, mengingat saat ini pengunjung kesenian ataupun seni teater boneka tidak hanya dari domestik saja. Guna pengembangannya, maka dibutuhkan suatu wadah berupa kompleks fasilitas seni teater boneka di Kota Surabaya tersebut. Konsep rancangan tatanan lahan yang memusat pada gedung pertunjukan, bentuk transformasi joglo jawa kastil, ruang yang natural modern, diharapkan dapat memberi sebuah acuan yang sesuai dengan kebutuhan, juga sebagai strategi perancangan untuk dapat mempertahankan, mengembangkan, melestarikan sebuah seni dan media pendidikan.

\section{Referensi}

Bappeda Jatim - Letak dan Kondisi Geografis Kota Surabaya, 2013, https://bappeda.jatimprov.go.id/bappeda/wp-content/uploads/potensi-kab-kota-2013/kotasurabaya-2013.pdf

Erdiono, D. (2011). ARSITEKTUR ' MODERN' NEO-VERNAKULAR DI INDONESIA. Jurnal Sabua, 3(3), 32-39.

Jencks, C. (1991). LANGUAGE OF POST-MODERN ARCHITECTURE. Rizzoli.

Latshaw, G. (2000). THE COMPLETE BOOK OF PUPPETRY. Dover Publications; Illustrated Edition. Malaka, T. (2015, April). MENDAULAT KOTA SURABAYA SEBAGAI KOTA PENDIDIKAN. Kompasiana Beyond Blogging. https://www.kompasiana.com/tamam.malaka/54f776dda333114c678b4587/mendaulat-kotasurabaya-sebagai-kota-pendidikan

Nalan, A. S. (2015). TEATER BONEKA SEBAGAI MEDIA PENDIDIKAN SEGALA USIA BERBASIS BUDAYA. Seminar Nasional Forum Dosen Indonesia 2015. https://scholar.google.co.id/citations?view_op=view_citation\&hl=en\&user=ipnZxKQAAAAJ\&c itation_for_view=ipnZxKQAAAAJ:UeHWp8X0CEIC

Santosa, Eko, Harwi Mardianto, Heru Subagiyo (2008). SENI TEATER JILID 2. In SENI TEATER JILID 2 (p. 47). Direktorat Pembinaan Sekolah Menengah Kejuruan. 